\title{
What Is Sex For? To Transmit the Genes of the Microbiome...
}

Philippe Gouillou ${ }^{1}$

Physics is like sex: sure, it may give some practical results, but that's not why we do it.

- Richard P. Feynman

Author's Note: This hypothesis has been first published online on the website Evopsy.com in French on December 30, 2013, and then in the 3rd Edition of Pourquoi les femmes des riches sont belles (DeBoeck, Belgium : Louvain La Neuve) published on July 22, 2014.

\section{Abstract}

The effectiveness of sex to make children is remarkably low and totally random: there is no doubt that as soon as possible other methods to procreate will be preferred. Yet humans have an enormous amount of sex, devote a great deal of their resources to it, and most of the time even seek to ensure that sex is not fertile. Why?

This article proposes that one of the essential purposes of sexual intercourse, and probably the most important one, is to transmit not our genes, but the genes of microbiome bacteria. This hypothesis makes it possible to explain not only the frequency of sexual intercourse but also of no fertilizing sexual behaviors, even risky ones.

This hypothesis is not yet proven but fits perfectly with what has already been demonstrated on animals and humans.

\footnotetext{
${ }^{1}$ Independant scholar: gouillou.com; evopsy.com
} 


\section{Article}

Sexual penetration (Penis In Vagina, PIV) represents a significant investment for the woman. In addition to the risk of injury by her partner (men are on average twice as strong as women), she risks catching diseases (penetration is the most invasive act after surgery), and even being impregnated, which would result in 9 months of pregnancy, and then years of having to care for a child. In such difficult conditions, it is understandable that women would be particularly cautious and try to avoid any sexual act that is not purely for reproductive purposes. However, this is not at all what we see. Actually, women have, on average, a number of PIV much higher than their number of children, and many women seek sex for pleasure or even have multiple partners. How can this contradiction be explained?

\section{A general model of sex and scarcity}

Human fertilization is a story of scarcity: the man who succeeds in impregnating a woman reserves 9 months to 1 year of her life, without even counting the time that she will devote to their child after that. This question of availability (which is not unique to the human species) requires men to be in strong sexual competition to reserve this rarity².

More generally, all other things being equal, distinguishing donor and receiver:

1. If the receiver has little availability, then:

- The donor:

- Must search for the maximum of receivers

- Must prevent other donors from reaching the receiver

- The receiver:

- Either must be careful and selective

- Either there is another internal selection process (e.g., sperm war)

\section{If the receiver has a lot of availability, then:}

- The donor:

- Must still search for the maximum of receivers

- Is less required to block other donors (but still a little)

- The receiver:

- Must search for the maximum number of donors

\footnotetext{
${ }^{2}$ What is more surprising in the human species is that women also experience a very strong sexual competition. The explanation is that men invest a lot in the education of children and are therefore also a rare resource that women covet. It's Male Parental Investment also known as Paternal Investment.
} 
Human fertilization is in case 1. above: it is enough to replace "donor" by "male" and "receiver" by "female" to have a synthesis of sexual relations ${ }^{3}$.

\section{Is sex really used to make children?}

There are, however, several points that contradict the application of the model above to human relations:

Sex is inefficient:

First, it has to be reminded that if sex is necessary to have children, it is remarkably inefficient, as is shown by the ratios: Robert J King Ph.D. gives the figure of 18,000 male orgasms per second for only 4 births, or $0.02 \%$ ( 1 / 4 500)! Even if it is difficult to get a precise number, it is easy to notice that most sexual intercourses do not lead to conception.

Use of contraception is widespread:

But this extremely low probability of conception is most often not perceived as a problem, but instead as a risk that remains, and history shows that humans have looked for ways to reduce it to zero. We find evidence of contraception attempts in many ancient civilizations, and even in our times contraceptive drugs are an important market.

Infertile acts are valued:

Independently of contraception, many of sexual acts practiced do not, per se, allow fertilization: oral sex, anal sex, etc. It must be noticed that same behaviors are found in many other species, implying that they are not explained by culture.

Risky sexual behavior is still common:

Despite all warning campaigns, unprotected sex with unknown partners is frequent.

Women do not show such a high level of selectivity:

Women are not as "cautious" as required by the model: they have much more sex with strangers than expected.

\section{The usual explanations}

Many types of explanations are advanced to resolve these contradictions, as per example:

\footnotetext{
${ }^{3}$ Excluding Paternal investment and fear of pathogens of course.
} 
Redundancy:

When the realization of an action is important enough for our fitness, our body does encourage us through several programs, including that of pure pleasure. Infertile sex can be partly explained by the fact that we respond to this redundant program.

\section{Creating or strengthening bonds:}

Orgasm causes the production of oxytocin ("the hormone of attachment") that will strengthen the links between sexual partners. It has been argued that this effect would have been selected for investment in children ${ }^{4}$. An extension of this explanation is the creation of strong bonds outside the couples (e.g.: sexfriends). In some tribes, women try to have sex with many men to get "secondary fathers" who will help in the caring of the child.

\section{Exchange Sex/Resources:}

Women can "sell" their scarcity to men, that is to exchange a (low) probability of being a father against tangible benefits. The problem with this hypothesis is that, as women, many men want sex without the risk of having a child.

\section{Spermwar:}

It is considered that in human species as in some others, the selection does not stop at the intercourse, but that there is a competition between sperms inside the body of the woman. To have sex with many men would be a way to increase this competition.

Genetic diversity:

The life of the child, and therefore the fitness of its mother, will depend on the adaptation of its immune system to the parasites he will encounter. As these are unknown, the woman must try to get children with diverse immune systems, that is with different fathers.

\section{Hypothesis: the influence of the microbiome}

All these hypotheses (and others) are probably part of the explanation. But we can go further by noticing that the contradictions with the model are entirely due to scarcity (case 1 . of the model above): it suffices to remove it (case 2 .) and they are perfectly resolved.

Our DNA is not the only genetic code carried by humans. It must be added that of all microbiota, which present two fundamental differences: the transmission of these bacteria is not limited by scarcity

\footnotetext{
${ }^{4}$ It is also the justification used Christian moralists to authorize sex that was not done for the purpose of fertilization.
} 
(case 2), and, to the opposite of the human DNA, in the case of the microbiota all partners are both donors and recipients.

Therefore, the hypothesis is that a fundamental objective of sex, probably the most important one, is to transmit the genes of the many bacteria that we carry and that these bacteria influence our behavior for this purpose.

\section{Discussion}

The idea that bacteria have an influence on sexual behavior is not new. For example, Richard Dawkins (2006, p. 247) had written:

"I do not know of any direct evidence that sexually transmitted diseases increase the libido of sufferers, but I conjecture that it would be worth looking into."

And Cochran, Ewald, \& Cochran (2000, pp 437-438):

"Phenomena that strongly reduce the evolutionary fitness of their bearers cannot be maintained by strictly genetic causation at frequencies far above the rates at which they could be generated by mutation. The fitness costs of male homosexuality place it in this category [124]. Perhaps more importantly, each of the hypotheses that have been put forward to explain male homosexuality have critical flaws that, if not sufficient to cause their outright rejection, are sufficient to severely weaken them.

\section{(...)}

In contrast with difficulties of noninfectious explanations of homosexuality, the hypothesis of infectious causation does not incorporate critical logical flaws or contradictions of fundamental biological principles. Indeed, anecdotal reports indicate that changes in human sexual orientation have occurred following changes in the limbic area due to trauma or infection [131, 132]. One possible route would be sexual, whereby homosexual behavior could facilitate spread because of the larger numbers of partners homosexual males may have on average, relative to heterosexual males. Alternatively, transmission could be partly or entirely by one or more nonsexual routes, and homosexual orientation be a side effect of the infection that is unrelated to transmission."

Also, the parasite Toxoplasma gondii has been shown to increase the attractiveness of male rats (Dass et al., 2011) and of humans (Borráz-León et al., 2022):

"infected men had lower facial fluctuating asymmetry whereas infected women had lower body mass, lower body mass index, a tendency for lower facial fluctuating asymmetry, higher self- 
perceived attractiveness, and a higher number of sexual partners than non-infected ones. Then, we found that infected men and women were rated as more attractive and healthier than noninfected ones."

The hypothesis defended here, however, differs by three novelties:

1. It is not limited to external parasites but includes the entire microbiome. Rather than of infectious origin of sexuality, we should rather speak of co-evolution (Johnston \& Foster, $\left.2018^{5}\right)$, that is to consider the human as a supraorganism.

2. It is not limited to homosexual relationships but includes all sexual intercourse, including all that could be fertile.

3. It proposes that the parasite transmission is not a side-effect of sexual intercourse but its main objective.

\section{Advantages}

To consider that sex has as main objective to transmit the genes of the microbiota and that they manipulate us for this purpose makes it possible to explain numerous behaviors:

- Non-fertile sexual behaviors do indeed have a goal of genetic transmission: they are just in favor of other species.

- Risky and hypersexual behaviors (same reason).

- The scraper shape of the penis is not intended only to pull sperm out (Gallup, 2003; Gallup \& Burch, 2006) or to reduce the acidity of the vagina, but also to extract the bacteria it contains.

- The relationship between sex and women's morale (Gallup et al., 2002, Burch \& Gallup, 2006) could be explained by the impact of the microbiome on depression (Goetz, A. T. \& Shackelford, T. K., 2006 ; Goetz, A. T. \& Shackelford, T. K., 2006).

- The Coolidge Effect ("the progressive decline in a male's propensity to mate with the same female combined with a heightened sexual interest in new females", Steiger et al., 2008)

- The link between pathogen disgust and women's preferences for masculinity (Jones et al., 2013)

\footnotetext{
${ }^{5}$ Johnston \& Foster (2018) propose that the influence of the microbiome on our behavior is not explained by the manipulation of one by the others, but by co-evolution.
} 


\section{The "how to"}

This hypothesis is based on two conditions:

1. Bacteria are transmitted during sex

2. These bacteria have an influence on the brain encouraging sexual intercourse

The first is more than proven. Sexual intercourse is the closest physical encounters two humans may have after surgery, making it the best way to transfer bacteria. For example, Kort et al. (2014) had found "an average total bacterial transfer of 80 million bacteria" during 10 seconds of intimate kiss ("French kiss"), the Sexually transmitted Diseases are well known, the vaginal microbiota is changed by sexual activity (Vodstrcil et al., 2017), etc.

The second is not proven in humans, but it is not an extreme hypothesis: the opposite would be the assumption that, at the opposite of what has been found in other species, bacteria have no influence, which would be difficult to support.

In fact, to influence human sexual behavior, bacteria just have to increase the libido of their host, and perhaps influence the target of the libido.

Humans, as other species, have a strong force driving them to have sexual relations, strong enough to make them have risky behaviors, the libido. In other species, many cases are known of parasites increasing the libido of their host. For example, Boyce et al. (2019) have found that the sexual behavior of cicadas is spectacularly modified by Massospora fungi, and Morell (2016) had reported a similar effect on amphibians.

And, of course, the increase of the attractiveness of the host (Borráz-León et al., 2022) would also have an effect.

\section{Synthesis}

To say the goal of sex is to transmit "our" genes, we have first to consider ourselves a supraorganism including the genes of our microbiome.

The hypothesis that some bacteria in the microbiome influence human behavior to encourage increased sexual intercourse, and even risky behavior, makes it possible to better explain non-fertile sexual behaviors and the obsession with contraception.

\footnotetext{
${ }^{6}$ A Superorganism is an organism composed of members of the same species (e.g.: ants' nest), a Supraorganism is an organism composed of members of different species.
} 
This hypothesis is not proven but fits with what has already been demonstrated on animals and humans.

This hypothesis does not replace the other approaches based on the transmission of human DNA (and in particular the spermwar theory: Goetz \& Shackelford, 2006) but complements them. 


\section{References}

Adamo, S. A. (2014). Parasitic aphrodisiacs: Manipulation of the hosts' behavioral defenses by sexually transmitted parasites. Integrative and Comparative Biology, 54(2), 159-165. doi:1010.1093/icb/icu036 Borráz-León, J. I., Rantala, M. J., Krams, I. A., Cerda-Molina, A. L., \& Contreras-Garduño, J. (2022). Are Toxoplasma-infected subjects more attractive, symmetrical, or healthier than non-infected ones? doi: $10.7717 /$ peeri.13122

Boyce, G. R., Gluck-Thaler, E., Slot, J. C., Stajich, J. E., Davis, W. J., James, T. Y., ... Kasson, M. T. (2019). Psychoactive plant- and mushroom-associated alkaloids from two behavior modifying cicada pathogens. Fungal Ecology, 41(3361), 147-164. doi:10.1016/i.funeco.2019.06.002

Burch, R. L. \& Gallup, G. G. (2006). The Psychobiology of Human Semen. in Female Infidelity and Paternal Uncertainty: Evolutionary Perspectives on Male Anti-Cuckoldry Tactics. (S. M. Platek \& T. K. Shackelford, Eds.) (p. 258). Cambridge University Press. ISBN: 0521845386. Chap. 8, pp 141-172

Cochran, G. M., Ewald, P. W., \& Cochran, K. D. (2000). Infectious causation of disease: an evolutionary perspective. Perspectives in Biology and Medicine, 3(43), 406-448.

Dandine-Roulland, C., Laurent, R., Dall'Ara, I., Toupance, B., \& Chaix, R. (2019). Genomic evidence for MHC disassortative mating in humans. Proceedings of the Royal Society B: Biological Sciences, 286(1899), 20182664. doi:10.1098/rspb.2018.2664

Dass, S. A. H., Vasudevan, A., Dutta, D., Soh, L. J. T., Sapolsky, R. M., \& Vyas, A. (2011). Protozoan Parasite Toxoplasma gondii Manipulates Mate Choice in Rats by Enhancing Attractiveness of Males. PLOS ONE, 6(11), e27229. doi:10.1371/journal.pone.0027229

Dawkins, R. (2006). The Selfish Gene (30th Anniv.). Great Britain: Oxford University Press. ISBN: 9780199291144.

Del Giudice, M. (2019). Invisible Designers: Brain Evolution Through the Lens of Parasite Manipulation. The Quarterly Review of Biology, 94(3), 249-282. doi:1010.1086/705038

Gallup, G. (2003). The human penis as a semen displacement device. Evolution and Human Behavior, 24(4), 277-289. doi:10.1016/S1090-5138(03)00016-3

Gallup, G. G., Burch, R. L., \& Platek, S. M. (2002). Does semen have antidepressant properties? Archives of sexual behavior, 31(3), 289-93. doi:10.1023/A:1015257004839

Gallup, G. G. \& Burch, R. L. (2006). The semen-displacement hypothesis: semen hydraulics and the intra-pair copulation proclivity model of female infidelity. in Female Infidelity and Paternal 
Uncertainty: Evolutionary Perspectives on Male Anti-Cuckoldry Tactics. (S. M. Platek \& T. K. Shackelford, Eds.) (p. 258). Cambridge University Press. ISBN: 0521845386. Chap. 7, pp 129-140.

Goetz, A. T. \& Shackelford, T. K. (2006). Mate retention, semen displacement, and sperm competition in humans. in Female Infidelity and Paternal Uncertainty: Evolutionary Perspectives on Male AntiCuckoldry Tactics. (S. M. Platek \& T. K. Shackelford, Eds.) (p. 258). Cambridge University Press. ISBN: 0521845386. Chap. 9, pp 173-190

Johnson, K. V.-A., \& Foster, K. R. (2018). Why does the microbiome affect behaviour? Nature Reviews Microbiology. doi:10.1038/s41579-018-0014-3

Jones, B. C., Feinberg, D. R., Watkins, C. D., Fincher, C. L., Little, A. C., \& De Bruine, L. M. (2013). Pathogen disgust predicts women's preferences for masculinity in men's voices, faces, and bodies. Behavioral Ecology, 24(2), 373-379 doi:10.1093/beheco/ars173

Kort, R., Caspers, M., van de Graaf, A., van Egmond, W., Keijser, B., \& Roeselers, G. (2014). Shaping the oral microbiota through intimate kissing. Microbiome, 2(1), 41. doi:10.1186/2049-2618-2-41

Libersat, F., Kaiser, M., \& Emanuel, S. (2018). Mind Control: How Parasites Manipulate Cognitive Functions in Their Insect Hosts. Frontiers in Psychology, 9(May), 572. doi:1010.3389/fpsyg.2018.00572 Morell, V. (2016). Fungus turns frogs into sexy zombies. Science, (March 1). doi:10.1126/science.aaf4130

Sherwin, E., Bordenstein, S. R., Quinn, J. L., Dinan, T. G., \& Cryan, J. F. (2019). Microbiota and the social brain. Science, 366(6465), eaar2016. 10.1126/science.aar2016

Steiger, S., Franz, R., Eggert, A.-K., \& Müller, J. K. (2008). The Coolidge effect, individual recognition and selection for distinctive cuticular signatures in a burying beetle. Proceedings of the Royal Society B: Biological Sciences, 275(1645), 1831-1838. doi:10.1098/rspb.2008.0375

Tung, J., Barreiro, L. B., Burns, M. B., Grenier, J.-C., Lynch, J., Grieneisen, L. E., ... Archie, E. A. (2015). Social networks predict gut microbiome composition in wild baboons. Elife, 4, e05224. doi:1010.7554/eLife.05224

Vodstrcil, L. A., Twin, J., Garland, S. M., Fairley, C. K., Hocking, J. S., Law, M. G., ... Bradshaw, C. S. (2017). The influence of sexual activity on the vaginal microbiota and Gardnerella vaginalis clade diversity in young women. PLOS ONE, 12(2), e0171856. doi:10.1371/journal.pone.0171856 


\section{Links (in French)}

- Psychiatrie : I'hypothèse parasitaire. Philippe Gouillou. Evopsy. 1 novembre 2004

- A quoi sert le sexe ? A transmettre les gènes du microbiome.... Philippe Gouillou. Evopsy. 30 décembre 2013

- Pourquoi les Femmes des Riches sont Belles : 3ème Edition 2014. Philippe Gouillou. Evopsy. 20 juillet 2014 